\title{
Configuración de la metáfora de la mujer negra como territorio (nación y naturaleza) en la película Chocó
}

Angie Lizeth Alvarado

Lina Marcela GonZÁLEZ ${ }^{\mathrm{I}}$

\section{Introducción}

Chocó es un largometraje colombiano dirigido por Jhonny Hendrix Hinestroza, que se estrenó en las salas de cine colombianas en el año 2012. Esta historia se centra en una joven mujer negra, Chocó, quien busca día a día el sustento para su familia en minas de oro, además de soportar a un marido que abusa sexualmente de ella, maltrata a sus dos hijos, se embriaga y es holgazán. La trama de la película gira alrededor de todo lo que debe hacer Chocó para conseguirle una torta de cumpleaños a su hija Candelaria a pesar de las precarias condiciones económicas en las que se encuentran.

De modo que este artículo se desarrolló a partir del análisis de contenido como método de investigación, que es entendido por el investigador Jaime Andréu Abela en su texto Las técnicas de Análisis de Contenido: Una revisión actualizada como:

Una técnica de interpretación de textos, ya sean escritos, grabados, pintados, filmados..., u otra forma diferente donde puedan existir

1 Estudiantes de la Facultad de Comunicación Social de la Universidad Santo Tomás. 
toda clase de registros de datos (...), [donde] el denominador común de todos estos materiales es su capacidad para albergar un contenido que leído e interpretado adecuadamente nos abre las puertas al conocimientos de diversos aspectos y fenómenos de la vida social. $(2001$, p. 2$)$

El principal recurso de este método para la recolección de la información es, en este caso, la lectura textual y visual de un corpus a partir de combinar "la observación y producción de los datos, y la interpretación o análisis de los datos" (Andréu, 2001, p. 2), de manera que al hacer el proceso de interpretación se pueda percibir las intenciones directas e indirectas que el autor y el mismo corpus pretende comunicar.

Inicialmente se parte de la metáfora de la mujer como nación, precisando algunos postulados que preceden a la película Chocó. Tal vez una de las imágenes más reconocidas de esta metáfora es la de la mujer sosteniendo la bandera de Francia en una mano y en la otra un fusil en el cuadro La liberté guidant le peuple de Eugène Delacroix, 1830. En esta obra, la figura femenina representa a la libertad, a la republica que nace de dicha idea. En el cine también ha habido experiencias significativas. Por ejemplo en las películas Bambú (1948) y Lucía (1968), y cómo desde la figura femenina se representa a la Cuba colonial y poscolonial, en un ejercicio de "feminización de la nación" (Donapetry, 2006), tal y como se analiza en el libro Imagi/nación: la feminización de la nación en el cine español y latinoamericano (2006) de María Donapetry.

No obstante, para el análisis de las escenas de la película se siguió la línea de María Mercedes Andrade en su ensayo Metáforas de una nación en crisis: una visión panorámica de la novelística del Nueve de Abril en la década del cincuenta (2013), donde aparte de hacer un análisis de la metáfora de la nación en relación con el amor, el romance y las relaciones heterosexuales, la autora realiza una comparación del cuerpo femenino y de la feminidad con la realidad del país que se presenta en las novelas que analizó. Entonces, si por un lado la imposibilidad de un amor entre personas de diferentes clase sociales sirvió para representar en la literatura la fragmentación social de Colombia en los años 50, el cuerpo de la mujer se utilizó como metáfora de la 
nación para mostrar “(...) la felicidad o infelicidad de la unión nacional" (Andrade, 2013, p. 35), y también para representar, a través de la sumisión y la humillación de la figura femenina, el sufrimiento de la nación. Asimismo, en el texto se afirma que la metáfora de mujer-nación también funcionó como una dicotomía: por un lado en relación a la fortaleza de la nación, representada, por ejemplo, en el personaje de Hortencia del libro El 9 de abril de Pedro Gómez Corena; o partir de su explotación, como en el caso del personaje de Olga en el libro Los elegidos: el manuscrito de B.K.

En continuación, se aborda la metáfora mujer-naturaleza (selva, medio ambiente), al ser considerada desde la perspectiva en la que la mujer es principalmente madre, la que da vida, y de forma similar la naturaleza que permite que exista la vida animal y vegetal, a la cual provee alimento, refugio y sustento. Pero frente a lo anterior hay diferentes perspectivas, como la de Paula Núñez, la cual enuncia en su texto Nación, paisajes y mujeres: Entre la metáfora, el desarrollo y el territorio, mencionando que al territorio se le "feminiza" según los intereses del Estado-Nación, en la medida en que hay ciertos lugares que por sus características geográficas se les relaciona con características femeninas, pues poseen belleza y potencial en términos de ser susceptible a las decisiones de un ente "masculinizado" (procesos de desarrollo) al que se le atribuyen las decisiones sobre este territorio a partir de lógicas paternalistas y disciplinarias, es decir, la naturaleza posee ciertos recursos, por lo que puede ser explotada y dominada, en el marco de las lógicas del progreso sin que ésta oponga resistencia (2013, p. 180). Núñez menciona que se evoca la metáfora mujer-naturaleza en la medida en que se apela a estrategias de desigualdad y subordinación, de este modo explica que una mujer en un principio puede verse como un ser indómito y rebelde, así como el territorio no explorado, y lo razonable es que se pueda ejercer un control sobre éste para regularlo (2013).

A lo anterior se suma la perspectiva de Kristhian Ayala en su texto Representaciones del imaginario de nación en la caricatura política del siglo XIX (1892-1896) donde destaca no solo a la proveedora explotada, sino también la imagen de la mujer dotada de virtudes, una madre que da vida (tierra fértil) y alimenta; una imagen que busca 
reivindicar a la naturaleza desde su perspectiva maternal, que establece una conexión especial con el hombre desde la dependencia de éste a la "madre" que es su sustento.

Retomando a Núñez, desde otras consideraciones, se ve a la mujer como un objeto estático, apelando a argumentos en torno a la belleza y la fragilidad que hay que proteger y preservar como fundamento de la dependencia, pero son espacios “educados”, diseñados para ser admirados por su hermosura intocable (ejemplo de ello son los parques naturales, su fauna y flora), con lo que se observa la capacidad de "construir naturaleza, disciplinando paisajes en un proceso homologable al disciplinamiento de los cuerpos” (2013, p. 197).

Así pues, a partir de los conceptos anteriormente definidos, para abordar el análisis del corpus, se parte de la concepción de metáfora a partir de lo planteado por George Lakoff y Mark Johnson en su libro Metáforas de la vida cotidiana (1998), como una forma de conocimiento que "estructura (al menos en parte) lo que hacemos y la manera en que entendemos lo que hacemos (...), [de modo que su esencia] es entender y experimentar un tipo de cosa en términos de otra” (p. 41). Además, estos autores afirman que las metáforas establecen principalmente el sistema conceptual de las personas, el cual es fundamental en la definición y construcción de las realidades cotidianas, es decir, las metáforas constituyen los sistemas de percepción, pensamiento y acción (Lacoff \& Johnson, 1998).

Por lo anterior, al abordar las metáforas mujer-naturaleza y mujer-nación, en términos de Lacoff y Johnson, se entiende que históricamente el concepto de mujer ha estructurado la forma como se percibe la figura femenina, es decir, la mujer como proveedora de recursos (naturaleza) y como la representación de los valores y dinámicas de un territorio. Así pues a través del análisis de algunas de las escenas del largometraje Chocó, se observó la manera como se construye, desde el lenguaje metafórico, la representación de la mujer en torno a las categorías ya mencionadas.

En primer lugar, para analizar la metáfora mujer-nación se toma la primera escena en la que Chocó es violada por su esposo. Aquí, Everlides, esposo de Chocó, llega ebrio a la casa en medio de la noche, y trata de tener sexo con ella a pesar de que ella finge estar dormida. 
No obstante, ella se rehúsa y Everlides, luego de un forcejeo, la somete, la golpea y la viola.

Según Elvira Sánchez-Blake, en su libro Patria se escribe con sangre en donde afirma que cuando la mujer es alegoría de la nación, "la madre patria", "su cuerpo solo es visto como sitio de intervención, penetración y apropiación”. (Sánchez-Blake, 2000, p. 79). En esta escena, el cuerpo de la mujer es violentado y humillado, y así como se utilizó para representar los difíciles tiempos del país en los años 50, según el ensayo de Mercedes Andrade, aquí el sometimiento y la violación representan el sufrimiento de la nación, por ejemplo, en el contexto de la guerra. También representa el sufrimiento de la región, pues según datos del Departamento Administrativo Nacional de Estadística (DANE) del 2015, en Chocó cinco de cada diez personas está en condiciones de pobreza. Además, del 2014 al 2015 el nivel de pobreza pasó del 63,1 por ciento al 65,9. (El Tiempo.com, 2015).

Dentro de esta misma línea está la escena en que Chocó le reclama a su esposo acerca del dinero de la alcancía que ella tenía guardado para el colegio de sus hijos. Aquí, Everlides la golpea y la lanza al suelo en la mitad de la calle. En este caso la violencia y la humillación pública se aseveran, el recordatorio de que desde su posición de mujer ella no debe levantarle la voz al marido.

La otra escena que se utilizó fue en la que Chocó reza a San Francisco. En esta, ella va a la iglesia luego de ser despedida de la mina, al ver que no cuenta con suficiente dinero para la torta y las necesidades de la casa. Al entrar a la iglesia entona una canción y luego se arrodilla a orar, lo cual alude a que no solo las violencias recaen en el cuerpo de la mujer, sino también que los valores nacionales se representan en ella, ya que sobre el personaje de Chocó recaen los ritos de la nación y de la región, como el pequeño altar que ella tiene en su casa, el canto a San Francisco, la estatuilla de la Virgen María, los cantos de su tierra, etc. Pero no solo se manifiestan en ella los valores religiosos sino también los sociales: Chocó es la madre "abnegada" que trabaja sin descanso por sus hijos, sin importar que su esposo, quien debería ser su apoyo, solo representa una carga más. Como mujer negra, lleva también acotados los valores de sus ancestros. Desde el trabajo que le acepta en la minería artesanal, hasta los cantos, la música y el baile, 
ella también representa a su región, y se reitera principalmente la imagen del negro explotado trabajando en la mina de oro.

En segundo lugar, retomando la escena en la que Chocó es abusada física y sexualmente, también puede verse evidenciada la metáfora mujer-naturaleza, en la medida en que se considera objeto de usufructo y dominación. Esta escena es contrastada con otras escenas en las que se ve la explotación minera, en otras palabras socavar la naturaleza, en este caso más visible, con uso de retroexcavadoras y mercurio.

De este modo, la mujer y la naturaleza se ven en circunstancias en las que, según Paula Núñez, refiere a la indefensión y la vulnerabilidad, de manera que la mujer y la naturaleza se toman como objetos estáticos del que se sustrae lo necesario, objetos que no oponen resistencia y que se ven forzados a someterse ante la violencia. En principio, cuando Chocó se niega a acceder a las peticiones de su marido, se puede observar el carácter de lo que se considera como la mujer indómita, así como el ambiente "caprichoso" que no quiere ceder a las necesidades del ser humano, en el marco de los procesos de desarrollo, y que posteriormente al ser tratadas violentamente se les controla y disciplina para que hagan lo que se requiera, según los intereses de su violentador.

Por otro lado, se observa la metáfora mujer-naturaleza cuando la figura femenina es representada e históricamente considerada como el sustento del hogar y la proveedora del mismo, ya que en las múltiples escenas se ve a Chocó trabajando en las minas de oro, como lavandera, cocinando, respondiendo por sus hijos e incluso viéndose obligada a patrocinar los vicios de su esposo. Esta situación es reiterativa en el transcurso del film como una de las imágenes centrales, así como se observa con el entorno natural, el cual provee al ser humano de los recursos y bienes precisos para su subsistencia. Además es posible señalar la dependencia de los seres humanos a esa naturaleza, y en el caso específico de Chocó, a esa figura femenina en la que está sustentada sus hijos y su esposo, y en general de los habitantes del contexto del film al depender del oro que provee la tierra y de los alimentos, como la plantación de plátanos que cuidaba don Américo el patrón de Chocó.

En consecuencia, es posible observar que a través de la metáfora, se construyen formas de conocimiento, en este caso, como estereotipos 
respecto a la mujer y a las comunidades negras, entendiendo el estereotipo como, "una idea o comportamiento caracterizados por su posibilidad de repetición automática a partir de un modelo anterior, anónimo o impersonal, cuyos principios de clasificación no se verbalizan” (Sumpf \& Hugues, como se citó en Jaramillo, 2010, p. 106). En este sentido, Mara Viveros Vigoya menciona en su texto Dionisios negros. Estereotipos sexuales y orden racial en Colombia, que los estereotipos "no son adquiridos por la experiencia, sino transmitidos y recibidos a través de la comunicación de masas o del medio social en el cual se desenvuelven las personas" (2006, p. 2), es decir, que los estereotipos se constituyen a través del lenguaje (conceptos metafóricos), y por consiguiente penetra los marcos de acción y de pensamiento.

Estas construcciones regulan las relaciones de los individuos (las formas en las que se constituyen y se desarrollan) en todos los ámbitos. Así pues Viveros explica, desde el ámbito de la sexualidad, que en ciertas ocasiones "la voluntad de "poseer" una mujer no es sólo la manifestación de una atracción sexual sino también el deseo de expresar su superioridad sobre ella (...) (2006, p. 9), superioridad que se construye y se evidencia a partir de los conceptos metafóricos en los que se enmarca a la mujer, como un objeto para ser dominado y en el cual recaen valores culturales y sociales, así como responsabilidades desde su figura de sustento que finalmente es violentada, lo cual se evidencia en la cotidianidad de Chocó.

En continuación, Viveros también menciona que "el lenguaje corporal, gestual y rítmico aparece como uno de los pilares más sólidos de diferenciación y de autodefinición de los negros" (pp. 3-4), y en Colombia este aspecto se considera como una característica de superioridad del mundo de lo negro. De modo que un aspecto a destacar de la película, en torno al personaje de Chocó, es la música. Ésta tiene un rol fundamental dentro de la producción pues, por un lado, es un aspecto cultural destacable de la región, y por el otro, juega un papel sutil pero importante en la vida de Chocó.

Por otro lado este film como narrativa heteronormativa (desde la perspectiva en que incluye hombres y mujeres desde la comunidad negra, que históricamente en los distintos discursos ha sido omitida o mencionada de forma estigmática), representa una situación actual en 
la que aún se cae en lugares comunes, es decir, las concepciones respecto a la mujer y a las comunidades negras son persistentes: en primer lugar, en la medida en que reitera el discurso de la mujer-nación y mujer-naturaleza, a partir del cual se ha designado la figura femenina históricamente; y en segundo lugar en la medida en que, desde la parte laboral, la situación de Chocó se enmarca en lógicas coloniales, encuadradas en la precariedad y en verse forzada a aceptar cualquier trabajo para sostener su hogar, y en general de la comunidad negra, siendo reiterativo el discurso en el que son explotados o forzados a trabajar por salarios absurdos mientras que los "blancos", en este caso los paisas, son dueños de minas o tiendas prosperas.

En continuación, en el personaje femenino también están implantadas las enseñanzas sobre las posiciones de género. Chocó muestra comportamientos pasivos frente a su esposo y transmite estos patrones de conducta a su hija a través de frases como "quién dijo que a los hombres se les dice bobos", o como ella le pide a su hija que se levante del único asiento que tienen en el comedor para que "el hombre de la casa” se siente. En Colombia violencias de género como la intrafamiliar y sexual representan cifras preocupantes, y Chocó representa a esa nación con muy profundos y arraigados comportamientos machistas. Pero, a la vez, Chocó también es resistencia. Al final de la película ella se rehúsa a seguir siendo botín de guerra, a seguir siendo violentada y se revela al atacar a su agresor.

\section{Chocó, la nación}

A través del análisis e interpretación del corpus se evidenció la construcción del discurso audiovisual de la película Chocó, a partir de conceptos metafóricos de mujer-nación y mujer-naturaleza, representando a la figura de mujer y madre afrocolombiana, en primer lugar, como portadora de unos valores y tradiciones nacionales, como lo son la religión, la música de la región y los ritos, y en segundo lugar, desde la explotación y la violencia que aquejan al país, reflejados en la violencia de género, el abuso sexual, el machismo y el racismo, ésta última representada principalmente en la explotación minera debido a las logias coloniales que giran en torno. 
Igualmente, la metáfora se construye a partir de la designación y relación de Chocó con el territorio, que lleva su mismo nombre, además de la constante reiteración de la explotación minera de la selva pacífica como una expresión literal de la mujer violentada y socavada desde su consideración como madre proveedora y responsable de su hogar.

Hacia el final, no obstante, Chocó también es representada como la mujer que se rehúsa a ser simplemente botín de guerra o blanco de la violencia, y deja su papel de sumisión, representando de este modo a la nación y a la región que se hartan de la explotación.

De igual manera se tiene en cuenta que este largometraje hace parte de lo que se ha llamado la nueva ola del cine colombiano, que se caracteriza por mostrar otros aspectos de la realidad del país, no necesariamente centrándose en el conflicto armado y el narcotráfico, por lo que Chocó es una muestra de esas nuevas narrativas, sin pretensiones y buscando simplemente reflejar cómo desde la cotidianidad de una región del país se evidencian otros tipos de conflictos sociales.

\section{Referencias}

Apuntes de la clase de Estudios Afrocolombianos y Afroamericanos a cargo del docente Jorge Iván Jaramillo de la Universidad Santo Tomás del primer periodo del año 2016.

Andrade, M. (2013). Metáforas de una nación en crisis: una visión panorámica de la novelística del Nueve de Abril en la década del cincuenta. Revista de Estudios Colombianos. No. 41, pp. 32-37. Recuperado de https://www. researchgate.net/publication/277328133_Metaforas_de_una_nacion_ en_crisis_una_vision_panoramica_de_la_novelistica_del_nueve_de_Abril

Andréu, J. (2001). Las técnicas de Análisis de Contenido: Una revisión actualizada. Centro de Estudios Andaluces. Recuperado de http://public. centrodeestudiosandaluces.es/pdfs/S200103.pdf

Ayala, K. (2012). Representaciones del imaginario de nación en la caricatura política del siglo XIX (1892-1896) (Tesis de Maestría). Pontificia Universidad Católica de Perú: Lima, Perú. Recuperado de http://tesis.pucp. edu.pe/repositorio/bitstream/handle/123456789/4630/AYALA_CALDERON_KRISTHIAN_REPRESENTACIONES.pdf?sequence=1

Donapetry, M. (2006). La feminización de la colonia y de la nación poscolonial. Imaginación: la feminización de la nación en el cine español y 
latinoamericano, pp. 51-59. Madrid, España: Editorial fundamentos. Recuperado de https://books.google.com.co/books?id=3DAg7qM1Fj4C\&pg=PA53\&lpg=PA53\&dq=metafora+de+la +mujer+como+nacion\& source $=$ bl\&ots $=51$ Ewwkd-ep\&sig $=$ A611AHIbhaToLCcG7dXZWPHYN5E\&hl=en\&sa $=X \& v e d=0$ ahUKEwj64Y-8nsHLAhVJLB4KHUCNC0cQ6AEITzAG\#v=onepage\&q=metafora $\% 20 \mathrm{de} \% 201 \mathrm{a} \% 20$ mujer $\% 20$ como $\% 20$ nacion $\& \mathrm{f}=$ false

El Tiempo.com (9 de junio de 2015). Chocó sigue con los peores indicadores de pobreza en el país. El Tiempo. Recuperado de http://www.eltiempo.com/economia/indicadores/ choco-el-departamento-mas-pobre-del-pais/15926096

Lacoff, G. \& Johnson, M. (1998). Metáforas de la vida cotidiana. Madrid, España: Cátedra

Núñez, P. (Noviembre, 2013). Nación, paisajes y mujeres: Entre la metáfora, el desarrollo y el territorio. Revista Nomadías. No. 18, pp. 179-201. Recuperado de http://www.nomadias.uchile.cl/index.php/NO/article/ viewFile/34592/36296

Sánchez-Blake, S. (2000). Epílogo. Patria se escribe con sangre, pp. 79. Barcelona, España: Anthropos Editorial. Recuperado de https://books. google.com.co/books?id=UFXsIODHNxQC\&pg=PP1\&lpg=PP1\&dq=patria+se+escribe+con+sangre\&source=bl\&ots=EbnQ8ci8Hq\&sig=PsZN_ bPGCkFI--S3_BBOOO8CdyE\&hl=es\&sa=X\&ved=0ahUKEwiy4eLE9fPMAhWISyYKHZC9D9YQ6AEILDAE\#v=onepage\&q=madre $\% 20$ patria\&f $=$ false

Sumpf, J. \& Hugues, M., como se citó en Jaramillo, J. (Julio-diciembre de 2010). Mestizos outsiders, negros ausentes. Presencias y ausencias de la cuestión negra y mestiza en las Crónicas del Río de la Plata en los siglos XVI y XVII. Revista Comunicación y Ciudadanía. No. 4, pp. 100-109. Recuperado de https://www.google.com.co/url?sa=t\&rct=j\&$\mathrm{q}=\&$ esrc $=\mathrm{s} \&$ source $=$ web\&cd $=2 \& \mathrm{cad}=\mathrm{rja} \&$ uact $=8 \& \mathrm{ved}=0$ ahUKEwi q25CLnvLMAhXCTSYKHbjrAr8QFggjMAE\&url=https\%3A\%2F\%2Fdialnet.unirioja.es\%2Fdescarga \%2Farticulo\%2F3707509. pdf\&usg=AFQjCNEkQdM0gIzNJ_0EG9PTslz3Eg1WMw

Viveros, M. (2006). Dionisios negros: sexualidad, corporalidad y orden racial en Colombia. Mestizo yo?: diferencias, identidad e inconsciente, En Figueroa, B., Sanmiguel, P. \& Restrepo, O. (ed.). Bogotá, Colombia: Grupo de Psicoanálisis de la Universidad Nacional de Colombia 



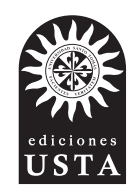

Esta obra se editó en Ediciones USTA, Departamento Editorial de la Universidad Santo Tomás. Se usó papel propalcote de 300 gramos para la carátula y papel bond beige de 75 gramos para páginas internas.

Tipografía de la familia Sabón. 
El espacio académico electivo Estudios Afrocolombianos y Afrolatinoamericanos tiene el placer de presentar el primer número de lo que será una publicación, un espacio, una apertura, una provocación donde empezarán a rodar todos los contenidos que se adelantan en los espacios académicos electivos de la Facultad de Comunicación Social, en especial los productos de los estudiantes al culminar estos espacios, los cuales se les da un valor en términos de prospectiva del programa y no se quedan en la re manida frase de "ah, es una electiva", todo lo contrario, se busca generar una tribuna desde donde se lean, se socialicen y den a conocer las producciones de los estudiantes que transitan estos espacios académicos.

Desde los productos de estos espacios electivos, los estudiantes proponen diferentes miradas, abordajes y maneras de visibilizar problemáticas y temas que están en completa conexión con la apuesta curricular del programa. Todo en la misma vía de cualificación y objetivo de no dejar muchas propuestas solo en el aula, sino dejar salir a volar diferentes escritos y trabajos entre lectores de diversos espacios. 